\title{
| Tables
}

2.1 Descriptive Summary of Variables Used in the Analysis of Hungarian Educational Opportunities

2.2 Effect of Social Background on Highest Year of Schooling Completed: Hungarian Men and Women Born Between 1911 and 1960

2.3 Effect of Social Background on Educational Transitions:

Hungarian Men Born Between 1911 and 1960

2.4 Effect of Social Background on Educational Transitions: Hungarian Women Born Between 1911 and 1960

3.I Distribution of Class Positions in First Job and at Age 30 by Respondent's Year of Birth

3.2 Distribution of Class Positions in Hungary in 1983:

All Respondents Aged 25 to 64

3.3 Gender Differences in Distribution of Class Positions in First Job and at Age 30 by Respondent's Year of Birth

4.I Selected Models Applied to 9 x 9 Intergenerational Mobility Classifications in Four Hungarian Birth Cohorts, Men Only

4.2 Selected Models Applied to 9 x 9 Intergenerational Mobility Classifications in Four Hungarian Birth Cohorts, Women Only 68

4.3 A Decomposition of Trends in Hungarian Intergenerational Mobility Under Model II*, by Gender

4.4 Maximum-Likelihood Scaling of Class Categories (Row and Column Effects) Under Model II* for Four Hungarian Birth Cohorts, by Gender (Intergenerational Tables)

4.5 Class Persistence Parameters Under Model II* for Four Hungarian Birth Cohorts, by Gender (Intergenerational Tables) 74

5.1 Selected Models Applied to 9 x 9 Work-Life Mobility Classifications in Four Hungarian Birth Cohorts, Men Only

5.2 Selected Models Applied to 9 x 9 Work-Life Mobility Classifications in Four Hungarian Birth Cohorts, Women Only 
5.3 A Decomposition of Trends in Hungarian Work-Life Mobility Under Model II*, by Gender

5.4 Maximum-Likelihood Scaling of Class Categories (Row and Column Effects) Under Model II ${ }^{*}$ for Four Hungarian Birth Cohorts, by Gender (Intragenerational Tables)

5.5 Class Persistence Parameters Under Model II* for Four Hungarian Birth Cohorts, by Gender (Intragenerational Tables) 94

6.1 Selected Examples of Nomenklatura Positions in Hungary 108

6.2 Description of Variables Used in the Analysis of Hungarian Elite Mobility

6.3 Demographic Characteristics of the Hungarian Nomenklatura Elite in 1988

6.4 Family Origins of the Hungarian Nomenklatura Elite in 1988

6.5 Educational Background of the Hungarian Nomenklatura Elite in 1988

6.6 Political Characteristics of the Hungarian Nomenklatura Elite in 1988

6.7 Social Networks of the Hungarian Nomenklatura Elite in 1988

6.8 Intragenerational Mobility Among the 1988 Hungarian Nomenklatura Elite

6.9 Determinants of Elite Membership in Post-Communist Hungary

6.10 Determinants of Surviving in Particular Elite Positions in Post-Communist Hungary 